\title{
The frequency of thelytokous parthenogenesis in European-derived Apis mellifera virgin queens
}

\author{
Rosalyn Gloag, Emily J. Remnant, Benjamin P. OldRoyd \\ Behaviour and Genetics of Social Insects Laboratory, Ecology and Evolution, School of Life and Environmental \\ Sciences, Macleay Building A12, University of Sydney, Sydney, NSW 2006, Australia \\ Received 8 November 2018 - Revised 20 February 2019 - Accepted 8 March 2019
}

\begin{abstract}
Thelytokous parthenogenesis is the asexual production of female progeny. In the honey bee, Apis mellifera, thelytoky is unknown from mated queens, but can occur in virgin queens that have been induced to lay. We used microsatellite markers to quantify theltyoky in virgin A. mellifera queens of European origin that were sham inseminated with saline and/or narcotised with carbon dioxide. Of 20 queens, 17 (85\%) produced at least one daughter thelytokously during an 8-week period. One exceptional queen produced $19 \%$ thelytokous progeny, though few total offspring ( 20 daughters in 107 pupae). The average proportion of thelytokous progeny among the remaining queens was $0.9 \%$ (range $0-3.5 \%$ ), with the balance being males. These results are consistent with observations from the pre-molecular biology era that virgin honey bee queens of non-African subspecies regularly produce thelytokous offspring at low frequency and indicate that there is significant natural variation in the capacity for thelytoky among these queens.
\end{abstract}

\section{thelytoky / parthenogenesis / Western honey bee / Apis mellifera / virgin queen}

\section{INTRODUCTION}

Male Hymenopterans typically arise from unfertilised eggs (Dzierzon 1845) by arrhenotokous parthenogenesis and are therefore haploid (White 1973). Females are normally produced sexually (Cook 1993; Crozier and Pamilo 1996) via the union of a sperm nucleus with an egg pro-nucleus. However, in some populations or species, females can arise via automictic thelytokous parthenogenesis (Rabeling and Kronauer 2013) (Figure 1). Under this form of parthenogenesis, meiosis proceeds as

Electronic supplementary material The online version of this article (https://doi.org/10.1007/s13592-019-00649-0) contains supplementary material, which is available to authorized users.

Corresponding author: R. Gloag, ros.gloag@sydney.edu.au

Manuscript editor: David Tarpy normal to produce four haploid pronuclei at the end of meiosis II. Then, two of the four pro-nuclei fuse, as if one acted as a sperm, thereby restoring diploidy and producing a female offspring that is essentially a clone of her mother (Suomalainen et al. 1987; Pearcy et al. 2006; Goudie and Oldroyd 2014). In social Hymenoptera, thelytoky can occur in queens or workers and has profound consequences for the kin structure of insect societies. For example, worker thelytoky means that unmated laying workers can be genetically reincarnated as the next queen, increasing the potential for reproductive conflict between sisters (Greeff 1996a, b; Goudie and Oldroyd 2014, 2018; Holmes et al. 2014). Reincarnation means that the benefits of reproductive cheating by thelytokous workers are far greater than for arrhenotokous workers that can only produce males (Greeff 1996a, b; Beekman and Oldroyd 2008; Goudie and Oldroyd 2018). In contrast, queen thelytoky can have the opposite effect of reducing kin conflict 


\section{Arrenotoky}
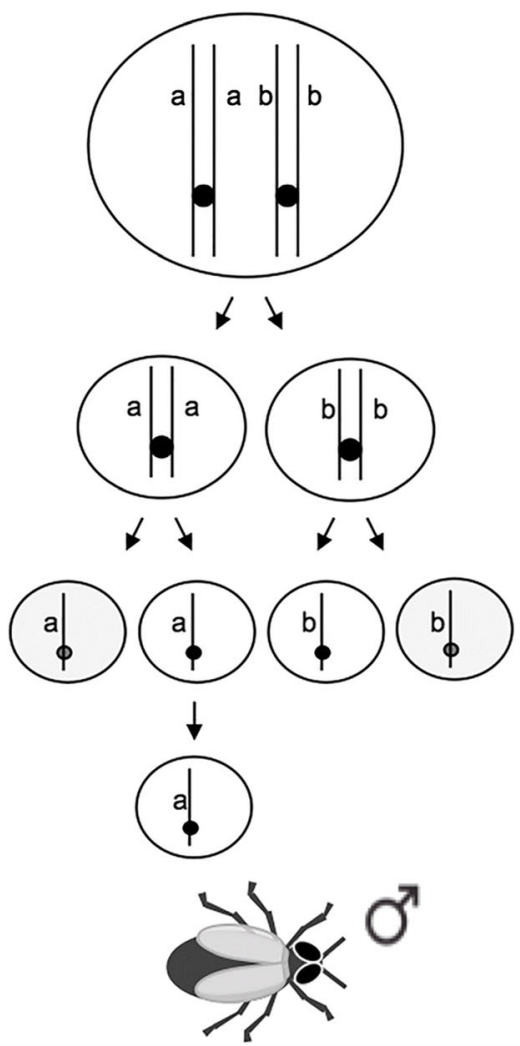

\section{Thelytoky}

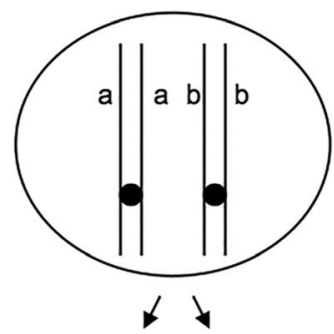

Meiosis I

Meiosis II
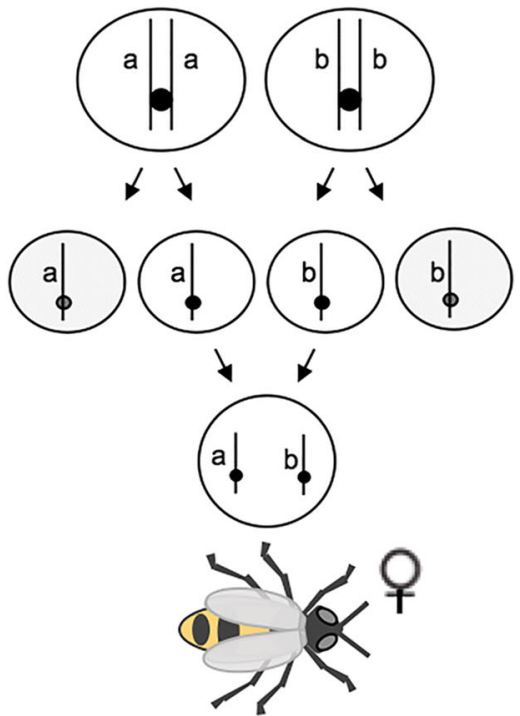

Figure 1 Male Hymenoptera (haploid) are produced via arrenotoky. Female Hymenoptera (diploid) are typically produced sexually, but can be produced via automictic thelytokous parthenogenesis when two of the four products of meiosis II fuse to restore diploidy.

over reproduction, by increasing the relatedness of both workers and queens (Rabeling et al. 2009).

In the honey bee Apis mellifera, the incidence of worker thelytoky differs markedly among lineages and subspecies (Hepburn et al. 1998; Chapman et al. 2015). A. mellifera can be grouped into four main evolutionary lineages: African (A lineage), Eastern European (C lineage), Western European (M lineage) and the Near East (O) lineage (Ruttner 1988; Franck et al. 2000). Thelytoky is rare in most subspecies of all lineages, but common among queenless workers of one A-lineage subspecies, A. m. capensis of the Cape provinces of South Africa (hereafter Capensis) (Onions 1912; Jack 1916; Anderson 1963). More than 50\% of Capensis workers produce female offspring via thelytoky (Aumer et al. 2017). Other African lineage subspecies, such as those from Tunisia (Anonymous 1892), may have similarly high frequencies of worker thelytoky. These differences across lineages are consistent with a genetic basis of thelytoky in honey bees. Indeed, in Capensis workers, thelytokous reproduction is thought to be controlled by a single locus in a simple Mendelian manner (Lattorff et al. 2005; Aumer et al. 2017; but see Chapman et al. 2015).

Thelytoky in honey bees is also known from virgin queens that have been prevented from mating naturally (Mackensen 1943) or experimentally induced to lay eggs via narcosis with carbon dioxide (Tucker 1958; Crewe and Allsopp 1994; 
Oldroyd et al. 2008). As in workers, the incidence of thelytoky in $\mathrm{CO}_{2}$ narcotised queens varies among evolutionary lineages. Two studies have reported a low incidence of thelytoky in $\mathrm{CO}_{2}$ treated virgin queens of European-origin. Mackensen (1943) reported around one third of virgin queens prevented from mating produced around $1 \%$ daughters (all other eggs being male). Similarly, Tucker (1958) found that around threequarters of virgin queens produced at least one thelytokous daughter when induced to lay by repeated carbon dioxide narcosis, with an average frequency of thelytoky per queen of less than $1 \%$. In contrast, almost all Capensis virgin queens induced to lay by double narcosis with carbon dioxide produce thelytokous offspring (Crewe and Allsopp 1994; Oldroyd et al. 2008). The frequency of thelytokous progeny is variable among Capensis queens, but is up to $100 \%$ (Crewe and Allsopp 1994; Oldroyd et al. 2008).

There is some evidence that thelytoky can be induced in Hymenopterans by interspecific matings (Tardieux and Rabasse 1988). When exotic A. mellifera queens were forced to mate with native $A$. cerana drones on Tsushima Island, Japan, about $3 \%$ of progeny were thelytokous (Nakamura et al. 1998). This frequency is similar to that observed in virgin queens of the $\mathrm{C}$ lineage (Mackensen 1943; Tucker 1958). Remnant et al. (2014) experimentally determined whether interspecific instrumental inseminations of A. mellifera queens with semen from A. cerana males would produce thelytokous offspring. In that experiment, five A. mellifera queens were successfully inseminated with $A$. cerana semen. Of these queens, three produced only males, one produced non-viable interspecific hybrids and one produced 24 males and one thelytokous worker.

During experimental work for the above study (Remnant et al. 2014), we sham-inseminated (hereafter SI) four European-derived A. mellifera queens (commercial Australian stock) with $0.3 \%$ saline solution and narcotised them twice for 10 min with $\mathrm{CO}_{2}$. That study focused on interspecific mating between honey bee species and the sham inseminations were originally intended as controls for treatments receiving interspecific semen. One of our SI queens, however, produced a high proportion of thelytokous offspring, comparable to that seen in some $\mathrm{CO}_{2}$-narcotised Capensis virgin queens (Crewe and Allsopp 1994; Oldroyd et al. 2008). This led us to conduct a further assessment of the incidence of thelytoky in virgin A. mellifera queens to (i) confirm previous estimates (Mackensen 1943; Tucker 1958) of its incidence in European lineages using molecular markers and (ii) determine the typical frequency of thelytoky following sham insemination with saline.

\section{METHODS}

We reared three batches of virgin queens of commercial Australian stock. Australia's commercial honey bees are hybrids of Western European and Eastern European ancestry (Chapman et al. 2016). The first batch was reared in spring 2012 in Cairns, Far North Queensland, Australia $(n=4)$ alongside the experimental setup for Remnant et al. (2014) (but previously unreported). The next two batches were reared in spring 2015 at the University of Sydney campus ( $n=14, n=11)$. Within each batch, we used queens grafted from a single queen-mother colony using standard queen-rearing techniques (Harbo 1986), with a different mother colony used for each batch. On emergence, queens were wing-clipped to permanently prevent mating and introduced into 4 -frame nucleus colonies to mature. The virgin queens were prevented from leaving their colonies via grids (queen excluders) tacked over the colony entrances.

The queens of batch 1 were sham-inseminated at 3-4 days of age with $2 \mu$ sterile saline solution $(0.03 \%)$ and narcotised with $\mathrm{CO}_{2}$ for $10 \mathrm{~min}$ on the following day (Harbo 1986). The instrumental insemination process involves $\mathrm{CO}_{2}$ narcosis during the procedure for about $5 \mathrm{~min}$; thus, all queens were narcotised twice in $24 \mathrm{~h}$. One queen did not lay within 3 days of insemination and was subjected to further narcosis when 10 and 13 days of age. This queen began laying at 14 days of age. Batch 2 queens were similarly SI and narcotised the following day. Batch 3 queens were narcotised for $10 \mathrm{~min}$, but without SI, to assess whether SI was contributing to rates of thelytoky. In these latter two batches, we exposed all queens to their 
first $\mathrm{CO}_{2}$ treatment at 10 days of age, matching the age-at-laying of the thelytokous queen in batch 1 .

We inspected the brood produced by each queen once a week for 5 weeks (batch 1) or 8 weeks (batches 2-3) following narcosis or until the queen disappeared. During these inspections, we looked for evidence of female brood among capped brood cells. The caps of brood cells containing developing workers are flat while those containing developing males are domed (Winston 1991). When a female pupa or suspected female (larva in flat-capped cell) was found, we removed it with forceps and stored it at $-20 \mathrm{C}$. We also collected 30 male pupa per colony to confirm that these were the sons of queens, and not the workers. Whenever we identified suspected female pupa, we photographed all frames of the colony containing brood and later estimated the proportion of total pupa (capped cells) that were female by counting all capped cells in the colony. For a subset of queens from batches 2 and 3 ( $n=$ 8), we also collected 50-100 eggs to confirm that we were not missing a significant proportion of thelytokous offspring because they failed to develop to the pupal stage. This might happen if multiple unfertilized eggs were laid into the same cell and male offspring always outcompete female offspring for space in the cell. The sample sizes of offspring genotyped per queen are given in Table S2. We collected all queens at the end of the inspection period for genetic analysis.

We extracted DNA from hind legs of pupae and queens, tissue from larva and whole eggs using 5\% Chelex solution (Walsh et al. 1991). We genotypedbatch 1 samples at five microsatellite loci: A107, A8, A88, B124 (Solignac et al. 2003) and csd (Oldroyd et al. 2008). We genotyped batch 2 and batch 3 samples at eight loci (A107, A88, Ap43, B124, A14, A29, A79 and A8, Solignac et al. 2003). We considered an individual to be the thelytokous offspring of the queen if it shared all its alleles with the queen at all loci and was heterozygous (indicating diploidy) at one or more loci (Allsopp et al. 2010). We expected, however, that at a few loci, thelytokous offspring would be homozygous, even when their mother was heterozygous. This is because, under thelytoky by central fusion, the pronuclei that fuse are each descended from the two different products of meiosis I (Figure 1). Whenever there has been recombination at meiosis I, alleles become shuffled between chromatids. This means that there is a $1 / 3$ chance that heterozygosity will be lost in offspring, relative to the parent, at any locus that was heterozygous in the mother and was free to recombine (i.e. the locus is unlinked to the centromere) (see Pearcy et al. 2006; Goudie and Oldroyd 2014 for detailed explanations of why this is the case). We considered an individual to be an arrhenotokous offspring of the queen if he carried only one of the queen's alleles at all loci.

\section{RESULTS}

Incidence of thelytoky in European-derived virgin A. mellifera

queens

Batch 1. Of the four queens sham-inseminated with saline prior to a second $\mathrm{CO}_{2}$ narcosis, one died shortly after insemination, and two produced only phenotypically male brood and were not considered further. The fourth queen that was narcotised repeatedly and did not begin laying until 14 days of age, eventually produced 107 offspring that survived to the pupal stage. These offspring included both males $(n=87)$ and females $(n=20)(18.7 \%$ thelytokous progeny; Table I).

Batch 2. Of 14 queens sham-inseminated with saline prior to a second $\mathrm{CO}_{2}$ narcosis, 8 survived beyond the first week posttreatment and laid eggs. Of these, seven queens produced a small number of worker offspring ( $n=1-10$ per queen) interspersed among a majority of male offspring (Table I; $0.1-2.4 \%$ thelytokous offspring), while the remaining one queen produced only very few $(<20)$ total eggs, all of which were male.

Batch 3. Of 11 queens treated with $\mathrm{CO}_{2}$ narcosis (but not sham-inseminated), all survived to lay eggs and 9 produced at least one thelytokous female offspring during the 8 weeks of the experiment ( $n=1-5$ per queen) among a majority 
of male offspring (Table I; $0.2-2.3 \%$ thelytokous offspring). In the other two queens, we detected only male offspring, although one of these queens produced very few eggs in total $(<20)$. The incidence of thelytoky was therefore similar between queens that were or were not sham-inseminated in addition to $\mathrm{CO}_{2}$ narcosis (batch 2 vs batch 3 : $p=0.36$, Fisher's exact test).

The genotypes of all female offspring were consistent with them being the thelytokous daughters of the queen (Table SI).

\section{DISCUSSION}

When induced to lay via carbon dioxide narcosis, most of the virgin A. mellifera queens we examined produced a majority of male brood but a low frequency of thelytokous daughters $(85 \%$ of all queens, $0.1-2.4 \%$ thelytokous brood per queen). This incidence is similar to that reported by Tucker (1958) and Mackensen (1943) for A. mellifera of commercial European stock.

One of our queens produced a relatively high proportion of thelytokous offspring (19\% of brood), making it an outlier for non-African A. mellifera. This queen was sham inseminated with saline solution in addition to double $\mathrm{CO}_{2}$ narcosis. However, another eight queens treated in the same way showed little or no thelytokous reproduction. Therefore, sham insemination does not consistently enhance the frequency of thelytoky in A. mellifera virgin queens. Indeed, the frequency of thelytoky in most of our SI queens was similar to that of queens that have simply been narcotised (this study, Tucker 1958), prevented from laying but not narcotised (Mackensen 1943), or inseminated with interspecific semen (Nakamura et al. 1998; Remnant et al. 2014; Gloag et al. 2017). Although our outlier queen did not begin laying until 2 weeks of age, the low incidence of thelytoky among other similarly aged queens in our experiment suggests that delayed onset of oviposition is also not an important factor causing thelytoky.
What then might explain the usually high incidence of thelytoky in this one queen? Her total reproductive output was lower than most queens examined in subsequent batches, largely because she laid eggs for the first 2 weeks of the experiment and then ceased laying. Tucker (1958) reported that thelytoky by virgin queens was most common in the days immediately after egg-laying began, so it is possible that the incidence of thelytoky in this queen would have been diluted over time had she continued laying. Even so, this queen remains a clear outlier in our study. She produced 20 thelytokous daughters within the first week of laying, compared to 0-3 daughters for the same period in all other queens. Our view, therefore, is that this queen represents the high end of natural variation in the genetic tendency towards thelytokous parthenogenesis in A. mellifera of European origin.

Why do virgin queens induced to lay by $\mathrm{CO}_{2}$ narcosis produce occasional thelytokous offspring whereas mated queens, and queens instrumentally inseminated with semen, apparently do not? The most obvious explanation is that thelytoky goes unnoticed in mated and inseminated queens because both thelytokous and sexually produced offspring are females that cannot be distinguished phenotypically. Since the development of microsatellite loci for honey bees 25 years ago (Estoup et al. 1993), tens of thousands of honey bee workers have been genotyped. Thus far, there are no reports of thelytoky in naturally mated queens, including in A. m. capensis (Beekman et al. 2009). Possibly, rare thelytokous workers from mated queens are overlooked as cases of allelic dropout or assumed to have fathers that carried the same allele as the queen at multiple loci.

The observation that almost all A. mellifera virgin queens produce thelytokous offspring at low frequency raises the question of whether laying workers can also produce the occasional female offspring. In one strain developed in Arizona, workers were frequently thelytokous ('Lusby bees', deGrandi-Hoffman et al. 1991), though the proportion of thelytokous vs arrhenotokous brood was not quantified in that study. Workers of the Asian honey bee Apis cerana, which begin egg-laying rapidly 
Table I. Number and proportion of thelytokous female offspring detected among otherwise male offspring of European-derived virgin A. mellifera queens following sham insemination (SI) and/or carbon dioxide narcosis $\left(\mathrm{CO}_{2}\right)$. Only queens that survived at least 1 week post-treatment and produced at least 20 eggs are shown. Asterisks (*) indicate that the female offspring were identified from egg genotypes only; all other female offspring were detected as pupa or larva in flat-capped cells.

\begin{tabular}{|c|c|c|c|c|c|}
\hline Batch & Treatment & Queen & No. female offspring & No. male offspring & $\%$ females among all offspring \\
\hline \multirow[t]{3}{*}{1} & \multirow[t]{3}{*}{$\mathrm{SI}+\mathrm{CO}_{2}$} & $1-1$ & 20 & 87 & 19.0 \\
\hline & & $1-2$ & 0 & 119 & 0.0 \\
\hline & & $1-3$ & 0 & 147 & 0.0 \\
\hline \multirow[t]{7}{*}{2} & \multirow[t]{7}{*}{$\mathrm{SI}+\mathrm{CO}_{2}$} & $2-1$ & 7 & 927 & 0.8 \\
\hline & & $2-2$ & 9 & 912 & 1.0 \\
\hline & & $2-3$ & 10 & 419 & 2.4 \\
\hline & & $2-4$ & 1 & 296 & 0.3 \\
\hline & & $2-5$ & 1 & 1043 & 0.1 \\
\hline & & $2-6$ & 1 & 953 & 0.1 \\
\hline & & $2-7$ & $1 *$ & 96 & 1.0 \\
\hline \multirow[t]{10}{*}{3} & \multirow[t]{10}{*}{$\mathrm{CO}_{2}$} & $3-1$ & 4 & 175 & 2.3 \\
\hline & & $3-2$ & 1 & 97 & 1.0 \\
\hline & & $3-3$ & 0 & 112 & 0.0 \\
\hline & & $3-4$ & 1 & 106 & 0.9 \\
\hline & & $3-5$ & 2 & 759 & 0.3 \\
\hline & & $3-6$ & 1 & 136 & 0.7 \\
\hline & & $3-7$ & 3 & 498 & 0.6 \\
\hline & & $3-8$ & 1 & 112 & 0.9 \\
\hline & & $3-9$ & 4 & 417 & 1.0 \\
\hline & & $3-10$ & $5^{*}$ & 143 & 3.5 \\
\hline \multicolumn{5}{|c|}{ Total average + SEM } & $0.9 \pm 0.2^{\mathrm{a}}$ \\
\hline
\end{tabular}

${ }^{\text {a }}$ Average is calculated from $N=19$ queens, excluding the outlier queen 1-1 (batch 1)

after becoming queenless, can produce rare females among a majority of male-destined eggs (Gloag et al. 2017), including females that are reared as queens (Holmes et al. 2014).

The occasional high incidence of thelytoky in the progeny of virgin C-lineage queens suggests that there is pre-existing genetic variation for thelytoky in most or all honey bee populations. Thelytoky, a mutation that most likely arises as a fault in cell division during early embryogenesis (Cole-Clark et al. 2017), can be selectively beneficial under some circumstances because it enhances the reproductive success of workers. Where thelytoky is common in a eusocial Hymenopteran population, it can give rise to unusual forms of social structures, including loss of the queen caste (Ravary and Jaisson 2002), hybridogenesis (Schwander et al. 2008), queen cloning (Fournier et al. 2005) and social parasitism (Jordan et al. 2008). The low but detectable frequency of thelytoky in most honey bee populations therefore emphasises that haplodiploidy acts as an exaptation for the evolution of novel social structures in the eusocial Hymenoptera (Aamidor et al. 2018).

\section{GENERAL SUMMARY}

Thelytokous parthenogenesis is the asexual production of female progeny (Figure 1). In social Hymenoptera, thelytoky can occur in queens or workers and has profound consequences for the 
kin structure of insect societies. In the honey bee, Apis mellifera, thelytoky is unknown from naturally-mated queens, but occurs in virgin queens that have been induced to lay eggs, usually at low frequency. In this study, we quantified the frequency of thelytokous parthenogenesis in virgin A. mellifera queens of European ancestry. We sham-inseminated queens at 3-4 days of age with $2-\mu$ sterile saline solution $(0.03 \%)$ and/or narcotised them with $\mathrm{CO}_{2}$ for $10 \mathrm{~min}$. Queens were wingclipped to permanently prevent mating and prevented from leaving their colonies via grids over colony entrances. We used eight microsattelite markers to confirm the origin of any female pupa that appeared in colonies. We considered an individual to be the thelytokous offspring of the queen if it shared all its alleles with the queen at all loci and was heterozygous (indicating diploidy) at one or more loci (Figure 1). Of 20 queens that laid eggs, 17 $(85 \%)$ produced at least one daughter thelytokously during an 8-week period (Table I). One exceptional queen produced $19 \%$ thelytokous progeny, though few total offspring (20 daughters among 107 pupae). The average proportion of thelytokous progeny among the remaining queens was $0.9 \%$ (range 0 $3.5 \%$ ), with the balance developing as males via arrenotoky. The incidence of thelytoky was similar for queens that were sham-inseminated during carbon dioxide narcosis and those treated with narcosis only. These results are consistent with observations from the pre-molecular biology era that virgin honey bee queens of non-African subspecies regularly produce thelytokous offspring at low frequency. The high incidence of thelytoky observed in one queen suggests that there is significant natural variation in the capacity for thelytoky in unmated A. mellifera queens.

\section{ACKNOWLEDGEMENTS}

We thank Maurice Damon for logistical help with inseminations. We performed batch 1 inseminations in the laboratories of Biosecurity Australia at Cairns airport, and sincerely thank James Walker tor the use of the facility. We thank Gabriele Buchmann for assistance with genotyping, and Eloise Hinson and Michael Duncan for assisting with sample collection and colony management.

\section{AUTHOR'S CONTRIBUTIONS}

BPO and RG designed the study, RG, BPO and EM performed experiments, $R G$ and EM analysed data, RG and BPO wrote the paper. All authors read and approved the final manuscript.

\section{FUNDING INFORMATION}

This work was funded by the Australian Research Council project DP150101985 to RG and BPO.

\section{OPEN ACCESS}

This article is distributed under the terms of the Creative Commons Attribution 4.0 International License (http://creativecommons.org/licenses/by/4.0/), which permits unrestricted use, distribution, and reproduction in any medium, provided you give appropriate credit to the original author(s) and the source, provide a link to the Creative Commons license, and indicate if changes were made.

La fréquence de la parthénogenèse thélytoque chez les reines vierges D'apis mellifera

Thélytoquie/ parthénogenèse / abeille occidentale / Apis mellifera / reine vierge

Thelytoke Parthenogenesefrequenz bei Apis mellifera Jungköniginnen europäischer Abstammung

Thelytokie / Parthenogenese / Westliche Honigbiene / Apis mellifera / Jungkönigin

\section{REFERENCES}

Aamidor S.E., B. Yagound, B.P. Oldroyd. (2018) Sex mosaics in the honeybee: how haplodiploidy makes possible the evolution of novel forms of reproduction in social Hymenoptera. Biol. Let. https://doi.org/10.1098 /rsbl.2018.0670.

Allsopp M.H., M. Beekman, R.S. Gloag, B.P. Oldroyd. (2010) Maternity of replacement queens in the 
thelytokous Cape honey bee Apis mellifera capensis . Behav. Ecol. Sociobiol. 64, 567-574.

Anderson R.H. (1963) The laying worker in the Cape honeybee Apis mellifera capensis. J. Apic. Res. 2, 85-92.

Anonymous. (1892) Fertile worker bees - their utility. Journal of Horticulture, Cottage Gardener and Home Farmer 25,134 .

Aumer D., M.H. Allsopp, H.M.G. Lattorff, R.F.A. Moritz, A. Jarosch-Perlow. (2017) Thelytoky in Cape honeybees (Apis mellifera capensis) is controlled by a single recessive locus. Apidologie 48, 401-410.

Beekman M., B.P. Oldroyd. (2008) When workers disunite: Intraspecific parasitism in eusocial bees. Ann. Rev. Ent. 53, 19-37.

Beekman M., M.H. Allsopp, L.A. Jordan, J. Lim, B.P. Oldroyd. (2009) A quantitative study of worker reproduction in queenright colonies of the Cape honey bee, Apis mellifera capensis. Mol. Ecol. 18, 2722-2727.

Chapman N.C., M. Beekman, M.H. Allsopp, T.E. Rinderer, J. Lim, P.R. Oxley, B.P. Oldroyd. (2015) Inheritance of thelytoky in the honey bee Apis mellifera capensis . Heredity 114, 584-592.

Chapman, N., Harpur, B.A., Lim J., Rinderer, T.E., Allsopp, M., Zayed, A., Oldroyd, B.P. 2016 Hybrid origins of Australian honey bees. Apidologie 47, 26-34.

Cole-Clark M.P., D.A. Barton, M.H. Allsopp, M. Beekman, R.S. Gloag, T.C. Wossler, I. Ronai, N. Smith, R.J. Reid, B.P. Oldroyd. (2017) Cytogenetic basis of thelytoky in Apis mellifera capensis. Apidologie 48, 623-634.

Cook J.M. (1993) Sex determination in the Hymenoptera: a review of models and evidence. Heredity 71, 421-435.

Crewe R., M. Allsopp. (1994) Sex and the single queen: recent experiments with capensis and scutellata queens. S. Afric. Bee J.. 66, 58-62.

Crozier R.H., P. Pamilo. (1996) Evolution of social insect colonies. Sex allocation and kin selection. Oxford University Press, Oxford.

Dzierzon J. (1845) Gutachten über die von Herrn Direktor Stöhr im ersten und zweiten Kapitel des GeneralGutachtens aufgestellten Fragen. Eichstädter Bienenzeitung 1: 109-113, 119-121.

Estoup A., M. Solignac, M. Harry, J.-M. Cornuet. (1993) Characterization of (GT)n and (CT)n microsatellites in two insect species: Apis mellifera and Bombus terrestris . Nuc. Acids Res. 21, 1427-1431.

Fournier D., A. Estoup, R.M. Orivel, J. Foucaud, H. Jourdan, J. Le Breton, L. Keller. (2005) Clonal reproduction by males and females in the little fire ant. Nature $435,1230-1234$.

Franck P., L. Garnery, M. Solignac, J.M. Cornuet. (2000) Molecular confirmation of a fourth lineage in honeybees from the Near East. Apidologie 31, 167-180.

Gloag R., K. Tan, Y. Wang, W. Song, W. Luo, G. Buchman, M. Beekman, B.P. Oldroyd. (2017) No evidence of queen thelytoky following interspecific crosses of the honey bees Apis cerana and Apis mellifera. Ins. Soc. 64, 241-246.
Goudie F., B.P. Oldroyd. (2014) Thelytoky in the honey bee. Apidologie 45, 306-326.

Goudie F., B.P. Oldroyd. (2018) The distribution of thelytoky, arrhenotoky and androgenesis among castes in the eusocial Hymenoptera. Ins. Soc. 65, 5-16.

deGrandi-Hoffman G., E.H. Erickson, D. Lusby, E. Lusby. (1991) Thelytoky in a strain of U.S. honey bees (Apis mellifera). Bee Science 1, 166-171.

Greeff J.M. (1996a) Effects of thelytokous worker reproduction on kin-selection and conflict in the Cape honeybee, Apis mellifera capensis. Phil. Trans. R. Soc. Lond. B. 351, 617-625.

Greeff J.M. (1996b) Thelytokous versus arrhentokous worker reproduction in the Cape honeybee and other eusocial Hymenoptera. Hereditas 124, 99-103.

Harbo J.R. (1986) Propagation and instrumental insemination, in: Rinderer T.E. (Ed.), Bee Genetics and Breeding, Academic Press, Orlando, pp. 361-389.

Hepburn H.R., S.E. Radloff, S. Fuchs. (1998) Population structure and the interface between Apis mellifera capensis and Apis mellifera scutellata. Apidologie 29, 333-346.

Holmes M.J., K. Tan, Z. Wang, B.P. Oldroyd, M. Beekman. (2014) Genetic reincarnation of workers as queens in the Eastern honeybee Apis cerana. Heredity 114, 65-68.

Jack R.W. (1916) Parthenogenesis amongst workers of the Cape honey-bee: Mr. Onions' experments. Transactions of the Entomological Society of London 3-4, 396-403.

Jordan L.A., M.H. Allsopp, B.P. Oldroyd, T.C. Wossler, M. Beekman. (2008) Cheating honeybee workers produce royal offspring. Proc. R. Soc. Lond. B 275, 345-351.

Lattorff H.M.G., R.F.A. Moritz, S. Fuchs. (2005) A single locus determines thelytokous parthenogenesis of laying honeybee workers (Apis mellifera capensis). Heredity $94,533-537$.

Mackensen O. (1943) The occurrence of parthenogenetic females in some strains of honey-bees. J. Econ. Ent. $36,465-467$.

Nakamura J., J. Takahashi, T. Yoshida, H. Hoshiba. (1998) Thelytokous parthenogenesis in interspecific-mated honeybee queens, in: Schwarz M.P. and Hogendoorn K. (Eds.), Proceedings of the XIII International Congress of IUSSI, XIII Congress of IUSSI, Adelaide, pp. 337.

Oldroyd B.P., M.H. Allsopp, R.S. Gloag, J. Lim, L.A. Jordan, M. Beekman. (2008) Thelytokous parthenogenesis in unmated queen honey bees (Apis mellifera capensis ): central fusion and high recombination rates. Genetics 180, 359-366.

Onions G.W. (1912) South African 'fertile worker bees'. Ag. J. Union S. Afric. 1, 720-728.

Pearcy M., O. Hardy, S. Aron. (2006) Thelytokous parthenogenesis and its consequences on inbreeding in an ant. Heredity 96, 377-382.

Rabeling C., D.J.C. Kronauer. (2013) Thelytokous parthenogenesis in eusocial Hymenoptera. Ann. Rev. Ent. 58, 273-292. 
Rabeling C., J. Lino-Neto, S.C. Cappellari, I. Dos-Santos, U.G. Mueller, M. Bacci. (2009) Thelytokous parthenogenesis in the fungus-gardening ant Mycocepurus smithii (Hymenoptera: Formicidae). PLoS ONE 48, e6781.

Ravary F., P. Jaisson. (2002) The reproductive cycle of thelytokous colonies of Cerapachys biroi Forel (Formicidae, Cerapachyinae). Ins. Soc. 49, 114-119.

Remnant E.J., A. Koetz, K. Tan, E. Hinson, M. Beekman, B.P. Oldroyd. (2014) Reproductive interference between honey bee species in artificial sympatry in Australia and China. Mol. Ecol. 23, 1096-1107.

Ruttner F. (1988) Biogeography and taxonomy of honeybees. Springer-Verlag, Berlin.

Schwander T., S.S. Suni, S.H. Cahan, L. Keller. (2008) Mechanisms of reproductive isolation between an ant species of hybrid origin and one of its parents. Evolution 62, 1635-1643.

Solignac M., D. Vautrin, A. Loiseau, F. Mougel, E. Baudry, A. Estoup, L. Garnery, M. Haberl, J.-M. Cornuet. (2003) Five hundred and fifty microsatellite markers for the study of the honeybee (Apis mellifera L.) genome. Molecular Ecology Notes 3, 307-311.
Suomalainen E., A. Saura, J. Lokki. (1987) Cytology and evolution in parthenogenesis. CRC Press, Boca Raton.

Tardieux I., J.M. Rabasse. (1988) Induction of thelytokous reproduction in the Aphidius colemani (Hym., Apidiidae) complex. Journal of Applied Entomology 106, 58-61.

Tucker K.W. (1958) Automictic parthenogenesis in the honey bee. Genetics 43, 299-316.

Walsh P.S., D.A. Metzger, R. Higuchi. (1991) Chelex (R) 100 as a medium for simple extraction of DNA for PCR-based typing from forensic material. Biotechniques 10, 507.

White M.J.D. (1973) Animal cytology and evolution. Cambridge University Press, Cambridge.

Winston M.L. (1991) The Biology of the Honey Bee. Harvard University Press, MA.

Publisher's note Springer Nature remains neutral with regard to jurisdictional claims in published maps and institutional affiliations. 